\title{
Dysfunctional Antithrombin III in Sick Premature Infants
}

\author{
MAUREEN ANDREW, PATRICIA MASSICOTTE-NOLAN, LESLIE MTTCHELL, AND \\ KAREN CASSIDY \\ McMaster University Medical Center, Hamilton, Ontario, Canada
}

\begin{abstract}
Antithrombin III, a major inhibitor of activated coagulation factors has low immunologic levels in the human infant. The objective of this study was to deermine if the antithrombin III molecule is fully functional in sick premature infants. The populations studied included: adult controls $(n=20)$, full term healthy infants $(n=18)$, sick premature infants on day $1(n=16)$ and at $>7$ days of age $(n=10)$, and infants with disseminated intravascular coagulation $(n=11)$. This was diagnosed in the presence of prolonged screening tests, decreased levels of fibrinogen, and platelets along with elevated fibrin degradation products. Plasma antithrombin III levels were measured biologically (chromogenic substrate S2238) and immunologically (radialimmunodiffusion), and expressed as a percent of adult pooled plasma. Crossed immunoelectrophoresis were performed in the presence and absence of heparin. The antithrombin III biologic/immunologic ratios for adults, healthy full term infants, and sick premature infants on day 1 of life were all near unity. In contrast sick premature infants beyond the 1 st wk of life and infants with disseminated intravascular coagulation had lower biologic activity compared to immunologic $(B / I=0.77 \pm$ $0.28,0.78 \pm 0.17, p<0.01)$, respectively. In all groups, the antithrombin III molecule was normal on crossed immunoelectrophoresis except for one infant with disseminated intravascular coagulation. Sick premature infants may acquire a dysfunctional antithrombin III molecule in the postnatal period. (Pediatr Res 19: 237-239, 1985)
\end{abstract}

\section{Abbreviations}

\section{AT-III, antithrombin III}

RDS, respiratory distress syndrome

BPD, bronchopulmonary dysplasia

DIC, disseminated intravascular coagulation

CIE, cross-immunoelectrophoresis

APTT, activated partial thromboplastin time

PT, prothrombin time

TcT, thrombin clotting time

EACA, $\epsilon$-amino caproic acid

Normal hemostasis depends on a delicate balance between the procoagulant and fibrinolytic systems and their respective inhibitors. AT-III, the major inhibitor for the coagulation system

Received June 25, 1984; accepted September 6, 1984.

Correspondence should be sent to Dr. Maureen Andrew, Department of Pediatrics, Room HSC-3N26E, McMaster University Health Sciences Centre, 1200 Main Street West, Hamilton, Ontario, Canada L8N $3 Z 5$.

Supported in part by the Ontario Ministry of Health Grant PR947E and Medical Research Council of Canada MA 7595 inhibits factors XIIa, XIa, IXa, Xa, plasmin, and thrombin (5). Healthy premature and full term infants have low levels of a normally functioning AT-III molecule at birth (30-50\% of adult values) $(3,7,13,16,22,35)$ but do not develop spontaneous thrombosis as do adults with similar inherited low levels of ATIII. The infants with thrombotic complications have other underlying disorders such as RDS, BPD, and DIC which may in turn be associated with even lower levels of AT-III $(2,16,26)$. The objective of this study was to determine if the AT-III molecule functions normally in these sick premature infants as conceivably a dysfunctional molecule would increase the risk of abnormal thrombosis.

\section{MATERIALS AND METHODS}

Study Population. Premature infants admitted to McMaster University Medical Center who had coagulation screens performed for clinical indications were eligible for the study. Sick premature infants without DIC on day $1(n=16),>$ day $7(n=$ $10)$, and infants with DIC within the 1st wk of life $(n=11)$ were studied. DIC was diagnosed in the presence of prolonged screening tests (PT, APTT), fibrinogen levels below $1.2 \mathrm{~g} /$ liter and elevated fibrin-related antigen. The infant's gestional age was determined according to the Dubowitz scoring method (12). No infants received fresh-frozen plasma within the $72 \mathrm{~h}$ prior to the study sample and all received $1 \mathrm{mg}$ of vitamin $\mathrm{K}$ intramuscularly on delivery. Cord blood samples were obtained from 18 healthy full term infants (37-42 wk gestation). In addition 20 healthy adults were studied. Informed consent was not obtained for the infants as cord samples were used in the full term infants and unused plasma samples from coagulation screens ordered for clinical indications were saved from the sick premature infants. Pertinent clinical information was obtained from the charts.

Coagulation tests. Blood samples $(1 \mathrm{ml})$ were obtained from newly placed nonheparinized umbilical lines or from a peripheral vein, and placed in polypropylene tubes containing $0.13 \mathrm{M}$ sodium citrate and $0.1 \mathrm{M}$ (EACA (1 part citrate-EACA to 9 parts blood). Cord blood was drawn immediately at birth from the umbilical cord vein and treated in an identical manner. Platelet-poor plasma was stored in polypropylene tubes at $-70^{\circ}$ $\mathrm{C}$ until assaying. Assays on all samples were performed in a blind manner at McMaster University Health Sciences Centre. The following tests were performed: APTT (6), PT (6), TcT, fibrinogen (11), and fibrin-related antigen (Thrombo Wellcot). The immunologic concentration of AT-III was determined by radial immunodiffusion as previously described (17) using commercially available antibodies (Atlantic Antibodies, Maynard Scientific, Mississauga, Ontario). The biologic levels of AT-III were determined by the ability to inhibit thrombin using the chromogenic substrate S-2238 (31) in the presence of heparin. CIE was achieved by the two dimensional immunoelectrophoresis technique of Laurell (18) as modified by Sas et al. (29) using 16.6 U/ 
Table 1. Coagulation data for sick premature infants

\begin{tabular}{|c|c|c|c|c|c|c|c|}
\hline Group & $n$ & PT (s) & APTT (s) & $\operatorname{TcT}(\mathrm{s})$ & $\begin{array}{c}\text { Fibrinogen } \\
\text { (g/liter) }\end{array}$ & $\begin{array}{c}\text { FDP } \\
\text { (g/liter) }\end{array}$ & $\begin{array}{l}\text { Platelets } \\
\times 10^{9} / \text { liter } \\
\end{array}$ \\
\hline Day 1 & 16 & $14.8 \pm 2.0^{*}$ & $79 \pm 15.3$ & $25 \pm 3.0$ & $2.4 \pm 1.2$ & & $163 \pm 78.4$ \\
\hline$\geq$ Day 7 & 10 & $12.8 \pm 1.0$ & $58 \pm 8.4$ & $25 \pm 4.8$ & $3.8 \pm 2.1$ & & $243 \pm 100.5$ \\
\hline $\mathrm{DIC}$ & 11 & $21.9 \pm 5.0$ & $148 \pm 67.9$ & $37 \pm 11.3$ & $0.89 \pm 0.32$ & $0.328 \pm 0.27$ & $54 \pm 28.1$ \\
\hline Normal & & $\leq 17$ & $\leq 90$ & $\leq 30$ & $\geq 1.5$ & $\leq 0.03$ & $150-400$ \\
\hline
\end{tabular}

$*$ Mean \pm SD

Table 2. Characteristics for sick premature infants at birth

\begin{tabular}{lcccc}
\hline \multicolumn{1}{c}{ Group } & $n$ & Wt $(\mathrm{kg})$ & $\begin{array}{c}\text { Gestational } \\
\text { age }(w k)\end{array}$ & $\begin{array}{c}\text { Apgar score } \\
\text { at 5 min }\end{array}$ \\
\hline Day 1 & 16 & $1.6 \pm 0.70^{*}$ & $30.0 \pm 3.3$ & $6.4 \pm 2.0$ \\
P Day 7 & 10 & $1.2 \pm 0.70$ & $30.5 \pm 3.4$ & $7.4 \pm 1.2$ \\
DIC (<day 7) & 11 & $1.0 \pm 0.51$ & $28.4 \pm 3.8$ & $5.9 \pm 2.2$ \\
\hline
\end{tabular}

* Mean \pm SD.

Table 3. Antithrombin III levels

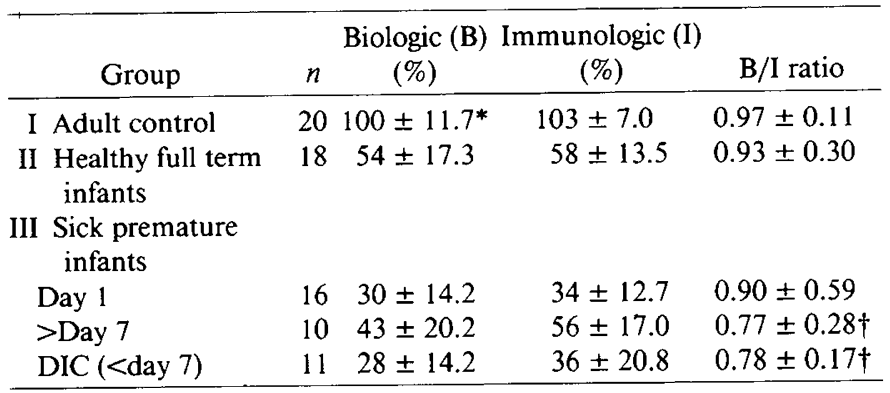

$*$ Mean $\pm \mathrm{SD}$

$\dagger$ Immunologic $>$ biologic value, paired Student's $t$ test, $(p<0.05)$.

$\mathrm{ml}$ of heparin in the first electrophoresis and $1 \%$ AT-III antiserum in the second. CIE was also performed in the absence of heparin in the first step and all control samples were diluted to the same antigenic concentration as the infants samples. Antithrombin activities and antigen levels are expressed as percent of a normal pooled plasma.

Results are expressed as means $\pm \mathrm{SD}$. Differences between means comparing immunologic to biologic samples were analyzed by Student's paired two-tailed $t$ test. $p$ values below 0.05 were considered to be significant.

\section{RESULTS}

Twenty normal adults, 18 healthy full term infants, and 37 sick infants admitted to the McMaster University Health Sciences Centre were studied. The infants samples were selected prior to AT-III determination to represent three groups: full term and premature infants with DIC $(n=11)$, premature infants on day 1 of life $(n=16)$, and premature infants $>7$ days of age $(n$ $=10$ ). No infant was present in more than one group. The premature infants on both day 1 and 7 had a similar incidence of RDS $(90 \%)$, and birth asphyxia (50\%). All premature infants were examined for the presence of DIC. Sick premature infants on day 1 and $>$ day 7 had normal coagulation profiles for their age while the infants with DIC had each of the abnormalities previously defined (Table 1). Their gestational age, birth weight, and apgar scores are given in Table 2 . The infants with DIC had lower birth weights and lower apgar scores at birth than the other two groups. Twelve infants died and autopsies were performed on six. Large vessel thrombosis were noted for three, one infant with DIC and two $>7$ days of age.

Equal levels of AT-III antigen and activity were measured for all adult controls, all healthy full term infants, and the majority of sick premature infants $(12 / 16)$ on day 1 of life (Table 3$)$. It is

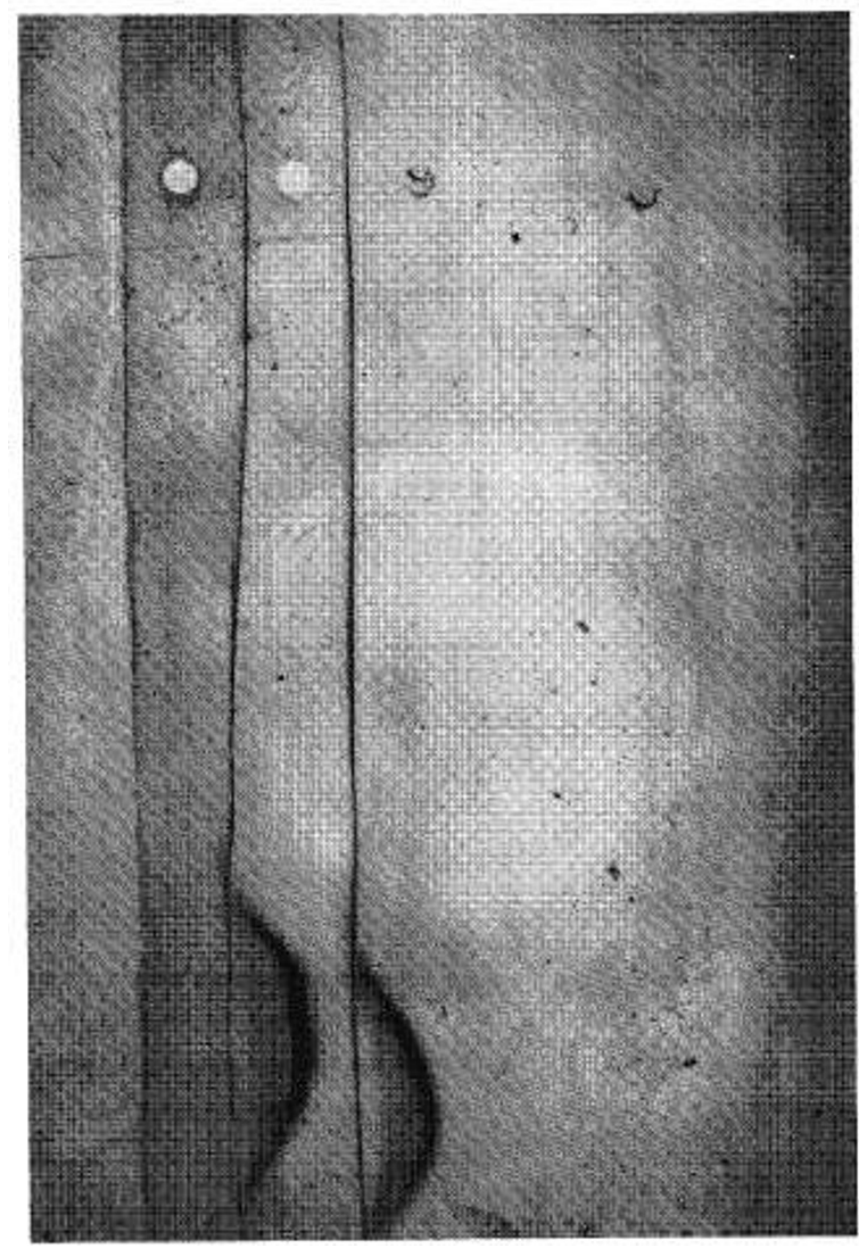

Fig. 1. CIE in the presence of heparin for an adult (upper) and for an infant with DIC (lower). The adult sample has been diluted to equal the antigen concentration of the infant sample. The latter shows an additional slow moving peak in the first dimension which shares identity with the normally present peak.

of some interest that four sick premature infants on day 1 had an AT-III B/I ratio $<0.6$. The CIE were normal in the presence or absence of heparin for these groups.

Sick premature infants $>$ day 7 and infants with DIC had lower biologic levels compared to immunologic levels $(p<0.01)$ (Table 2). Their CIE were also normal in the presence or absence of heparin except for one full term infant with DIC secondary to persistent severe acidosis. For this infant the CIE showed a slower migrating peak in the second dimension which shared identity with the peak normally present (Fig. 1). Although two peaks are usually observed in the presence of heparin, none of the other infants or the diluted controls had the normally present smaller slower migrating peak, presumably because of the very low antigen concentration of these samples. Other published CIE in infants were also missing the smaller slower migrating peak (4). 


\section{DISCUSSION}

AT-III levels are normally low in the newborn and are dependent on a number of perinatal factors. Levels of AT-III increase with increasing gestational age and postnatal age in healthy infants achieving values in the lower adult range as early as at $1 \mathrm{wk}$ of age $(3,16)$. AT-III from both premature and full term cord blood has been isolated and is identical to AT-III from adults with respect to a variety of functional and immunologic properties thus excluding the possibility of a fetal form of AT-III $(16,21)$. This study confirms those reports; however, we observed a dysfunctional AT-III molecule later in the postnatal period in a select population of sick premature infants. Previously infants with RDS and DIC have been reported to have lower levels of AT-III compared to age-matched controls $(3,16,26)$; however, AT-III antigen and activity have not been compared for these infants.

Discrepancies between immunologic and biologic activities of AT-III may either be inherited or acquired. The hereditary thrombophilias associated with a dysfunctional antithrombin III molecule are a rare and heterogeneous group. For some cases $(8$, $23,25,32)$ a qualitative AT-III deficiency was proposed based on the lack of correlation between AT-III antigen levels and ATIII activity, similar to our observation. Others have noted an abnormal affinity for heparin and two-dimensional immunoelectrophoresis in the presence of heparin has revealed two peaks of AT-III $(28,30,33,36)$. The dysfunctional AT-III in this study appears to be an acquired, not an inherited, phenomena. It is therefore unlikely that an abnormal molecule is being produced as is the case for the hereditary thrombophilias.

In adults the same type of acquired dysfunctional AT-III may occur in states of protease generation such as DIC, pancreatitis, and shock (14). Radiolabeled studies show that AT-III binds to thrombin to form complexes during in vivo thrombin generation (10). AT-III-protease complexes have an abnormal mobility on CIE with the presence of a slower migrating peak $(1,19,28)$. We have observed this pattern in one full term infant with severe persistent DIC, however, it was not present in the other 10 infants with DIC. A second form of acquired AT-III dysfunction could be due to acquired damage to the circulating AT-III molecule. In support of this hypothesis discrepancies between immunologic and biologic activities have been reported for other coagulation proteins such as factors XII (2), prekallikrein (15), and $\alpha_{1}$ antitrypsin (9) in the sick neonate.

Thrombotic complications occur in the newborn infant, although the precise incidence is unknown $(4,24,34)$. The majority of infants who develop thrombotic complications are premature infants with RDS, some of whom also have DIC. In our study, of the 12 premature infants who died, six had autopsies and of these three showed evidence of thrombosis in large vessels. These three infants had low biologic activity that was less than $50 \%$ of the corresponding immunologic levels. Although adults with hereditary thrombophilia may have abnormal thrombosis (5), it is an oversimplification to assume that the low levels of AT-III and its abnormal function are solely responsible for the occurrence of thromboses in these infants. In support of this, AT-III infusions, to neonates with RDS, are not affecting clinical outcome (27). Other conditions which contribute to thrombus formation in adults also exist in the newborn (5). Whether the dysfunctional AT-III reported here is a marker for a pathologic process or is responsible for thrombotic complications in the neonate has not been determined.

Acknowledgment. The authors acknowledge the excellent technical assistance of the McMaster University Medical Centre Coagulation Laboratory.

\section{REFERENCES}

1. Andersson LO, Engman L, Henningsson E 1977 Crossed immunoelectrophoresis as applied to studies on complex formation. The binding of heparin to antithrombin III and the antithrombin-III-thrombin complex. J Immunol Methods 14:271

2. Andrew M, Bhogal M, Karpatkin M 1981 Factors XI and XII and prekallikrein in sick and healthy premature infants. N Engl J Med 305:1130

3. Andrew M, Massicotte-Nolan PM, Karpatkin M 1983 Plasma protease inhibitors in premature infants: influence of gestational age, postnatal age and health status. Proc Biol Exp Med 173:495

4. Barnard DR, Hathaway WE 1979 Neonatal thrombosis. Am J Pediatr Hematol Oncol 1:235

5. Bick RL: 1982 Clinical relevance of antithrombin III. Semin Thromb Hemost $8: 276$

6. Biggs, R: (ed) 1976 Human Blood Coagulation, Hemostasis and Thrombosis. Blackwell Scientific Publications, London

7. Biland L, and Duckert F 1973 Coagulation factors of the newborn and his mother. Throm Death Haemorrh 29:644

8. Brozovic M, Stirling Y, and Hamlyn AM 1978 Thrombotic tendency and probable antithrombin deficiency. Thromb Haemost 39:778 (1978).

9. Bruce MC, Boat TF, Martin RJ, Dearborn DG, and Fanaroff A: 1981 Inactivation of alph, proteinase inhibitor in infants exposed to high concentrations of oxygen. Am Rev Respir 123:166 (abstr)

10. Chandra S, Bang N, and Marks C 1976 Radiolabelled AT-III as a probe for the detection of activation of blood coagulation in vivo. Thromb Res 9:9

11. Clauss A 1957 Gerinnungspisysiologische schnellmethode zur bestinimung des fibrinogens. Acta Haematol 17:237

12. Dubowitz LMS, Dubowitz V, and Goldberg C 1970 Clinical assessment of gestational age in the newborn infant. J Pediatr 77:1

13. Foley ME, Clayton JK, and McNicol GP 1977 Haemostatic mechanisms in maternal, umbilical vein and umbilical artery blood at the time of delivery. Br J Obstet Gynaecol 84:81

14. Gallimore JJ 1980 Discrepancies between antigen concentrations and functional activities of plasma protease inhibitors. Peptides Biol Fluids 28:345

15. Gordon EM, Ratnoff OD, Saito H, Gross S, and Jones PK 1980 Studies on some coagulation factors (Hageman factor, plasma prekallikrein, and high molecular weight kininogen) in the normal newborn. Am J Pediatr Hematol Oncol 2:213

16. Hathaway WE, Neumann LL, Borden CA, and Jacobson LJ 1978 Immunologic studies of antithrombin III heparin cofactor in the newborn. Thromb Haemost 39:624

17. Johnston M, and Zipursky A 1980 Microtechnology for the study of the blood coagulation system in newborn infants. Can J Med Tech 42:159

18. Laurell, CB 1972 Electroimmuno assay. Scand J Clin Lab Invest 124:(suppl) 21

19. Mackie I, Howarth D, and Brozovic M 1977 Antithrombin III immunoprecipitation Pattern 10:159 (1977).

20. McCarthy K, Bhogal M, Nardi M, and Hart D 1984 Pathogenic factors in bronchopulmonary dysplasia. Pediatr Res 5:483

21. McDonald MM, Hathaway WE, Reeve EB, and Leonard B 1982 Biochemical and functional study of antithrombin III in newborn infants. Thromb Haemost 47:56

22. Mullen AD, Van Doorm JM, and Hemker HC 1977 Heparin-like inhibitor of blood coagulation in the normal newborn. Nature 267:616

23. Nagy I, and Lozonczy H 1979 Three types of hereditary antithrombin III deficiency. Thromb Haemost 42:187

24. Oppenheimer EH, and Esterly JR 1965 Thrombosis in the newborn; comparison between infants of diabetic and nondiabetic mothers. J Pediatr 67:549

25. Penner JA, Hassohna H, Hunter MJ, and Chockley MA 1979 A clinically silent antithrombin III defect in an Ann Arbor family. Thromb Haemost 42:186

26. Peters M, Cate JW, Breederveld C, DeLeww R, Emesis J, and Koppe J: 1983 Low antithrombin III levels in neonates with idiopathic respiratory distress syndrome: Poor prognosis. Pediatr Res 18:273

27. Potron G, Leroux B, Droulle C, Santepne B, and Poymard A 1983 Efficiency of antithrombin treatment in newborn infants with respiratory distress syndrome. Thromb Hemost 50:48 (abstr)

28. Sas G, Blasko G, Banhegyi D, Jako J, and Palos LA 1974 Abnormal antithrombin III (antithrombin III "Budapest") as a cause of familial thrombophilia. Thromb Death Haemorrh 32:105

29. Sas G, Pepper DS, and Cash JD 1975 Investigations on antithrombin III in normal plasma and serum. Br J Haematol 30:265

30. Sas G, Peto I, Banhegyi D, Blasko G, and Domjan G 1980 Heterogeneity of the "classical" antithrombin deficiency. Thromb Haemost 43:133

31. Scully MF, and Kakkar VV 1977 Methods for semi micro or automated determination of thrombin, antithrombin, and heparin cofactor using the substrate nitroanalide, H-D-Phe-Pip-Ang-p<.2HCL. Clin Chim Acta 79:595

32. Sorensen PJ, Dyerberg J, Stoffersen E, and Krogh Jensen M 1980 Familial functional antithrombin III deficiency. Scand J Haematol 24:105

33. Tran, TH, Bounameaux H, Bondeli C, Honkanen H, Marbet GA, and Duckert F 1980 Purification and partial characterization of a hereditary abnormal antithrombin III fraction of a patient with recurrent thrombophlebitis. Thromb Haemost 44:87

34. Wade-Evans T 1961 Thrombi in the hepatic siniesoids of the newborn and their relation to pulmonary hyaline membrane formation. Arch Dis Child $36: 286$

35. Weissback G, Domula M, Lenk H, and Schneider P 1974 The progressive antithrombin activity and its relations to other factors of the coagulation system in newborns. Acta Paediatr Scand 67:555

36. Wolf M, Boyer C, Lavergne JM, and Larrifh MJ 1982 A new familial variant of antithrombin III: Antithrombin III Paris. Br J Haematol 51:285 